the uranium opposite the insulated polished aluminium, a deviation of $-84 \mathrm{sc}$. divs. from the metallic zero was found in about half a minute. After that the electrometer reading remained steady at this point, which we may call the uranium rays-zero for the two metals separated by air which was traversed by uranium rays. If, instead of having the uranium opposite to the aluminium, with only air between them, the uranium was wrapped in a piece taken from the same aluminium sheet, and then placed opposite to the insulated polished aluminium disc, no deviation was produced Thus in this case the rays-zero agreed with the metallic zero.

With polished copper as the insulated metal, and the uranium separated only by air from this copper, there was a deviation of about + ro sc. divs. With the uranium wrapped in thin sheet aluminium and placed in position opposite the insulated copper disc, a deviation from the metallic zero of $+43 \mathrm{sc}$. divs. was produced in two minutes, and at the end of that time a steady state had not been reached.

With oxidised copper as the insulated metal, opposed to the ranium with only air between them, a deviation from the metallic zero of about $+25 \mathrm{sc}$. divs. was produced.

When the uranium, instead of being placed at a distance of one centimetre from the insulated metal disc, was placed at a distance of two or three millimetres, the deviation from the metallic zero was the same.

These experiments show that two polished metallic surfaces connected to the sheath and the insulated electrode of an electrometer, when the air between them is influenced by the uranium rays, give a deflection from the metallic zero, the same in direction, and of about the same amount, as when the two metals are connected by a drop of water.

\section{THE EXTRACTION OF GOLD BY CHEMICAL} METHODS.

FXCLUDING mechanical, smelting, and amalgamation processes, the methods of extracting gold from its ores may conveniently be grouped together under the heading of wet or chemical methods. In these, the gold is dissolved by some suitable solvent, and is then separated from the unaltered ore by washing, and recovered by precipitation. The processes owe their origin to the rapid advance in the science of chemistry which has been made during the present century, and, although they are now of vast importance, and give results which would astonish our grandfathers, it is, perhaps, somewhat surprising that chemistry has not done more for the gold-mining industry. At the present day, the wet methods produce little more than a tenth of the total output of gold, while mechanical improvements in the old processes, made during the last half-century, are probably answerable for four or five times as much

Gold exists in nature practically only in one form, the metallic state, and the differences in treatment of the ores are necessitated by the variations in the physical condition of the metal, and by changes in the other constituents of the rock. Where the particles of gold are large enough to be seen by unassisted vision, they can usually be collected by means of mercury, and, on the other hand, are not dissolved in a reasonable time by any of the solvents of gold yet applied in practice. In these cases, therefore, chemical methods are not advantageous. Nevertheless, it usually happens that some, if not all, of the gold in an ore is in an extremely fine state of division. It has recently been shown by Edman that a great proportion of the gold in American ores consists of particles less than diameter, and that some of these are less than $\frac{1}{12000}$ inch. Sometimes, gold in an ore is not visible even under the micro scope, though readily detected by chemical means. Metal in such a condition is far more readily dissolved by a mobile liquid than by a viscous one like mercury, which does not wet the grains of sand between which the gold is hidden. Moreover, mercury may be prevented from doing its work by the presence of substances on which it exerts chemical action, such as the sulphides of antimony, or arsenic, or which protect the gold from its action by coating the particles with insoluble films.

From such causes as these, it has long been recognised that the treatment of gold ores by mercury is very imperfect in a great many cases. The method is, speaking generally, unsatisfactory in extracting gold contained in pyrites or other sulphides, and it is in the treatment of these substances that the chlorination process, now nearly fifty years old, has its main value.
Chlorine is a somewhat slow solvent for gold, but the time occupied by it in dissolving the fine flakes existing in pyrites is not excessive. Unfortunately, chlorine has a strongly preferential action on sulphides, and, to avoid the enormous waste of the gas which is entailed in the oxidation of a small percentage of these substances, it is necessary to precede chlorination by careful and complete roasting. Even in the rare cases, such as that of the Mount Morgan ore, in which the use of chlorine on completely oxidised ores is found to be desirable, the preliminary roasting is not omitted, as the percolation of liquids through the roasted mass is far easier than through the raw ore.

After roasting, there is little difficulty in the process. Oxides of the metals, except the alkaline earths, are very slowly attacked by chlorine; and when the alkaline earths are present salt is added in the roasting furnace. Here one of the sources of loss in the process is encountered, chloride of gold being formed and volatilised at all temperatures above $200^{\circ}$, when conmon salt is mixed with the ore. In long-bedded furnaces, however, this loss is reduced to a minimum ; chloride of gold is prevented from formation by the presence of large quantities of unoxidised pyrites, and when formed, in the oxidised product in the hottest part of the furnace, it is in great part decomposed and re-absorbed during its passage over the bed of comparatively cool ore, which has just been charged into the furnace.

It was formerly the universal practice to apply the chlorine to the slightly-damped roasted ore in the form of gas, and this method has never been entirely abandoned. Subsequently, after Dr. Mears had discovered that compressed chlorine was more rapid in its action than the same agent under ordinary atmospheric pressure, strong aqueous solutions were used, the ore being agitated with the solvent in revolving barrels. This practice is still adhered to in several works in the United States. Elsewhere, however, it has been completely set aside. For example, at Mount Morgan, in Queensland, the largest chlorination mill in the world, stationary vats have been reverted to, aqueous solutions of chlorine being, however, still used. At this mill about I, 500 tons of ore are treated every week at a cost of about $18 \mathrm{~s}$. per ton, or little more than one-sixth of the value of the yield in gold.

After the ore has been treated with chlorine for a period varying in different mills from an hour to one or two days, the liquid is filtered off and the gold precipitated by ferrous sulphate, sulphuretted hydrogen, or charcoal. As regards the relative advantages of these methods, it may be noted that charcoal only acts well with boiling solutions, and that sulphuretted hydrogen is now recommended by its advocates even when copper is present in the ore, Rothwell having recently pointed out that in acid solutions there is partial precjpitation, all the gold being removed from solution before the copper begins to come down.

The chlorination process, though perhaps unrivalled in the percentage of extraction which can usually be attained, labours under two serious disadvantages. Roasting the ore is often so expensive as to be impracticable, and the silver is, in any case, all lost. Both of these disadvantages are avoided by the use of the cyanide process. This was introduced by MacArthur and the Forrests after prolonged researches, having for their object the discovery of some chemical process which would not require a preliminary roasting of the ore.

The action of cyanide solutions on the precious metals had long been known. Elsner had stated, in 1846 , that the presence of air was necessary for the dissolution of gold or silver by potassium cyanide, and, subsequently, it was suggested that the action was represented by the equation

$$
4 \mathrm{Au}+8 \mathrm{KCy}+\mathrm{O}_{2}+2 \mathrm{H}_{2} \mathrm{O}={ }_{4} \mathrm{KAuCy}_{2}+{ }_{4} \mathrm{KHO} \text {. }
$$

This equation has recuntly been established by Maclaurin (Jour. Chem. Soc, vol. lxiii. (1893) p. 724 ; vol. lxvii. (I895) p. 199), who also showed that the dissolution of gold and silver becomes slower in proportion as free oxygen is more and more carefully excluded from the system. Thus, when a plate of gold was treated with a solution containing $I$ per cent. of cyanide of potassium in a stoppered bottle filled with oxygen, the loss of weight was 0.24 gramme in 96 hours; in a shallow vessel exposed to the air, the loss was 0.00835 gramme in 24 hours, and in a flask, freed from air as completely as possible, the loss was only 0.0002 gramme in the same time. In addition, Maclaurin prepared the curves of solubility of gold and silver in cyanide solutions, and showed that the maximum rate of dissolution of both metals is reached at 0.25 per cent. of $\mathrm{KCy}$, and 
diminishes slowly as the concentration is increased, and rapidly if it is decreased.

These results are in perfect accord with the experience gained in practice on a large scale. Before Maclaurin's papers were published, the favourite stock solution in South Africa had for some time been one containing from 0.25 to $0^{\circ} 30$ per cent. of cyanide, although weaker solutions are also used with excellent effect. Moreover, the difficulties introduced by a lack of free oxygen in the ore have long been severely felt. In particular, when concentrates containing much pyrites are treated, the absorption of oxygen by the sulphides is so rapid that the dissolution of gold is soon checked and becomes extremely slow. Thus, while goldleaf floating on cyanide solutions is dissolved in a few minutes, and, if submerged, in a few hours, the films of gold in pyrites, which are probably similar in thickness to gold-leaf, often take two or three weeks in going into solution.

This is so far from satisfactory that many efforts have been made to increase the speed of action of cyanide in some way. An artificial supply of oxygen, or air forced through the charge of ore and solution, was found to shorten the time required but to increase the waste of cyanide, and similar results follow from the use of various oxidising agents, such as manganese dioxide, hydrogen peroxide, and bleaching powder.

Greater interest attaches to the proposal made by Sulman and Teed to add bromide of cyanogen to ordinary cyanide solutions (Trans. of the Inst. of Mining and Metallurgy, vol. iii. (1895), p. 202). They put forward the equation

$$
\mathrm{CyBr}+3 \mathrm{KCy}+2 \mathrm{Au}=2 \mathrm{KAuCy}_{2}+\mathrm{KBr}
$$

as expressing the action which takes place, but no direct proof has yet been afforded of the validity of this equation. These experimenters are, however, convinced that oxygen plays no part in the action, and, consequently, that except for the fact that the edges only of the films of gold in pyrites are presented for attack, solution of the gold in concentrates is as rapid as that in quartzose ores. This view is borne out by a number of trial on half-ton lots of ore, although no results of actual working have yet been published. Even when there is full access of air, however, as in the case of gold-leaf floating on the solution, the addition of cyanogen bromide greatly increases the rate of action of potassium cyanide, and if air and bromine are together passed through a solution of cyanide, the rate is increased about 100 times.

Slowness of action in dissolving gold is of more importance than may at first sight appear, for it must be remembered that alkaline cyanides attack many of the constituents of gold ores at varying rates, and, therefore, that the longer the solution is left in contact with the ore, the greater will be the decomposition of the cyanide, and, consequently, the greater the total cost of the process. Decomposing pyrites (especially if sulphide of copper is present) are, when not in perfect contact with gold, particularly active in destroying cyanide, and, in order to partially prevent their effect, it is customary to neutralise ores which have been rendered acid by the formation of sulphates by "weathering." The neutralisation is effected by the addition of a solution of caustic soda, or, more usually, of lime to the ore before it is treated with cyanide. The destruction of cyanide, however, still goes on to a limited extent in such cases, and treatment is rendered practicable only by the preferential or more rapid action of very dilute solutions of cyanide on gold as compared with their action on the sulphides.

The relative rates of action of cyanogen bromide on gold, and on the various sulphides and oxides met with in ores, remain un determined, or at any rate unpublished, and until more light is thrown on these, either by laboratory experiments or by practical work on a large scale, it is impossible to judge what may be the future of the process. From some experiments, already made, it would appear that cyanogen bromide suffers considerable decomposition when placed in contact with some of the minerals met with in gold ores, and so it may happen that in many cases the haloid compound will be destroyed before it has time to get fairly to work in dissolving the gold.

The gold is recovered from solution either by its precipitation and replacement in solution by a metal positive to it in cyanide solutions, or by electro-deposition. The only metal largely used in practice is zinc, the action being one of direct replacement, expressed by the equation

$$
2 \mathrm{KAuCy}_{2}+\mathrm{Zn}=2 \mathrm{Au}+\mathrm{K}_{2} \mathrm{ZnCy}_{4} .
$$

It has been found necessary to use the zinc in a fine state of division, and the filaments, prepared by turning zinc in a lathe, are certainly more efficient than other forms. The shavings are no more than $0^{\circ} \mathrm{I} \mathrm{m} . \mathrm{m}$. in thickness, and $0.5 \mathrm{~m} . \mathrm{m}$. in width. When packed in spongy form they weigh about six or seven lbs. per cubic foot and can be ignited by a lucifer match, burning readily to zinc oxide. They must be freshly turned, as in practice the cyanide solutions are too dilute to clean dirty surfaces by dissolving hydrates or carbonates of zinc.

The action of the zinc is undoubtedly aided by the presence of lead, which exists as an impurity in commercial zinc to the extent of about 1 per cent., and by the iron gratings on which the filaments rest. Galvanic couples are thus formed, which assist in starting the action. Nevertheless, precipitation of the gold is at first slow, especially in very dilute solutions, and it is only after some gold has been thrown down, and the gold-zinc couple formed, that the action becomes fairly vigorous. When the amount of gold in solution bas fallen to about 0.0003 per cent., or from $I \frac{1}{2}$ to 2 dwts. per ton of liquid, the action again becomes slow, and this amount is left unprecipitated in practice, but, as the solutions are used again on fresh charges of ore, no loss of gold occurs.

The black slimy deposit of gold, or alloy of gold and zinc thus formed, is washed and sieved off from the undecomposed zinc as far as possible, and is dried, roasted, and melted down with borax, carbonate of soda, and other fluxes, with or without a previous treatment with dilute sulphuric acid. The bullion thus obtained is very base, containing about 700 of gold per Iooo, and variable quantities of zinc, lead, copper, and other metals. It is subject to the disadvantage that assay pieces, taken in the ordinary way, frequently differ in composition from the ingot taken as a whole.

The recovery of the gold from cyanide solutions by electrodeposition is the basis of the Siemens-Halske process. In this process the kathodes are of iron, and the anodes of lead foil. A very large surface is given to the electrodes, I2, 000 square feet of surface of lead being exposed in the treatment of 70 tons of solution per day at the Worcester Mine in the Transvaal. At stated intervals, the lead anodes, containing from 2 to 12 per cent. of gold, are removed, melted down, and cupelled. The bullion produced is very fine, but the cost of precipitation appears to be greater than that by the zinc process, the main items being the lead and iron consumed. The current needed is only about 0.06 ampere per square foot, the power required being about $5 \mathrm{~h}$.p. in the treatment of 70 tons of solution per day. The process makes but slow progress, only a small proportion of the gold produced by cyanide on the Rand beirg obtained in this way. $T$. K. Rose.

\section{AGRICULTURAL TEACHING AT OXFORI."}

THE present Professor of Rural Economy at Oxford has made use of the opportunity, afforded by the occurrence of the centenary of the foundation of his professorship, to discuss the general question of agricultural teaching in our Universities. After an interesting description of the life and work of Sibthorp, formerly Professor of Botany at Oxford, who literally gave up his life for the study of natural history on the shores of Greece, Prof. Warington proceeds, in the first place, to consider the important developments, both in the subject and in the means of teaching, which have taken place during the past century. He says:-

"The point on which I want to fix attention is the wholly different position in which agriculture stands at the present day from that which it held a hundred years ago. A hundred years ago agriculture was an art, having few points of contact with natural science. At the present time, both the materials and the operations of agriculture have been so far examined and elucidated by patient scientific investigation, that we may now fearlessly give the title of 'Agricultural Science' to the edifice of true theory which has been constructed. We need not shrink from making this claim because the theoretical edifice is still incomplete, for this incompleteness of theory is the normal condition of the natural sciences; what we assert is, that the whole field of agriculture is now occupied by the

1 "Agricultural Science : its place in a University Education." A lecture delivered before the University of Oxford, on November 5,1896 , on the occasion of the centenary of the foundation by Dr. John Sibthorp of the chair of Rural Economy, by Robert Warington, M.A., F.R.S., Sibthorpian Professor of Rural Economy. (London: Henry Frowde, 1896.)

NO. I 428 VOL. 55] 